\title{
A Droga da Obediência: Medicalização, Infância e Biopoder - Notas Sobre Clínica e Política
}

The Drugs Of Obedience: Medicalization, Childhood And Biopower -Notes On Clinic And Politics

La Droga De La Obediencia: Medicalizaciòn, Infancia Y Biopoder - Anotaciones Sobre Clínica Y Política

Kely Magalhães Decotelli, Luiz Carlos Teixeira Bohrer \& Pedro Paulo Gastalho de Bicalho

Universidade Federal do Rio de Janeiro

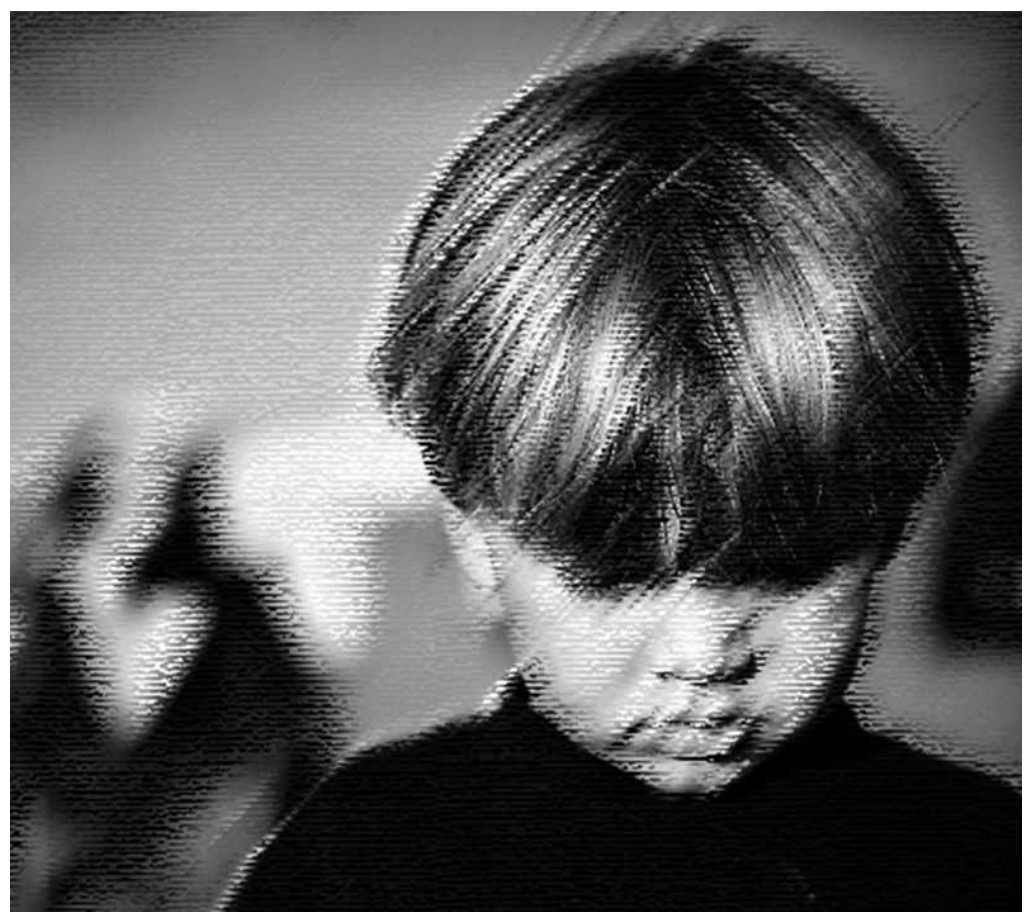


Resumo: A questão do não aprendizado na escola vem sendo alvo de inúmeras pesquisas em diversas áreas do conhecimento, e, sobremaneira, na Psicologia. Parte das discussões gira em torno de indicar as origens ou as causas, em que se destaca o transtorno de déficit de atenção e hiperatividade, um problema orgânico, da alçada médica, cuja solução seria a Ritalina. Assim, rapidamente como se constitui o problema, se diagnostica e se resolve. Este artigo propõe uma reflexão acerca do não aprender, analisando de que forma isso é tomado como um problema, sendo a infância, ela mesma, forjada e apreendida sob o escopo da Medicina. Como disparador dessa questão, recorremos a uma abordagem crítica do uso abusivo da Ritalina e ao conceito de biopolítica, que situa a gênese do saber médico no controle das formas de vida, constituindo um saber sobre os modos de viver, de ser criança. Muitas vezes, a Psicologia, como disciplina e campo de saber, incide nessa seara corroborando os processos de medicalização da vida. Propomos uma outra prática, imersa na problemática gênese biopolítica: uma clínica-política, na qual a Psicologia possa reapropriar-se das constituintes cognitivas e coletivas que compõem essa temática.

Palavras-chave: Distúrbios da atenção. Distúrbios da aprendizagem. Infância. Política educacional. Medicalização.

\begin{abstract}
The issue of non-learning in school has been the subject of several studies in many areas of knowledge and, above all, in Psychology. Part of the discussion concerns the indication of the origins or causes, which highlights the attention deficit and hyperactivity disorder, an organic problem, from medical competence, whose solution would be Ritalin. As soon as the problem is provided, it is diagnosed and solved. This article proposes a reflection about the "non-learning", analyzing how this is taken as a problem, being childhood itself forged and seized under the scope of medicine. Taking this fact as a trigger of this issue, we turn to the criticism regarding the abusive use of Ritalin and the concept of biopolitics that places the genesis of medical knowledge in the control of forms of life, what becomes a knowledge about ways of living, of being a child. Often, psychology as a discipline and field of knowledge joins this ground supporting the processes of medicalization of life. We propose a further practice, immersed in the problematic biopolitic genesis: a political clinic, where psychology can reappropriate the cognitive and collective constituents that compose this theme.
\end{abstract}

Keywords: Attention déficit disorder. Learning disabilities. Childhood. Educational policy. Medicalization.

Resumo : La cuestión del no aprendizaje en la escuela viene siendo objetivo de innumerables investigaciones en diversas áreas del conocimiento, y, principalmente, en la Psicología. Parte de las discusiones gira en alrededor de indicar los orígenes o las causas, en que se destaca el trastorno de déficit de atención e hiperactividad, un problema orgánico, de cuño médico, cuya solución sería el Ritalin. Así, rápidamente como se constituye el problema, se diagnostica y se resuelve. Este artículo propone una reflexión acerca del no aprender, analizando de qué forma eso es tomado como un problema, siendo la infancia, ella misma, forjada y aprehendida bajo el lente de la Medicina. Como disparador de esa cuestión, recurrimos a un abordaje crítico del uso abusivo del Ritalin y al concepto de biopolítica, que sitúa el génesis del saber médico en el control de las formas de vida, constituyendo un saber sobre los modos de vivir, de ser niño. Muchas veces, la Psicología, como disciplina y campo de saber, incide en esa área corroborando los procesos de medicalización de la vida. Proponemos otra práctica, inmersa en la problemática génesis biopolítica: una clínica política, en la cual la Psicología pueda reapropiarse de las constituyentes cognitivas y colectivas que componen esa temática.

Palabras clave: Transtorno de la atención. Transtorno del aprendizaje. Infancia. Política educacional. Medicalización.

1 Trechos de matéria exibida pela Globo

News em 12/11/2010.

Recuperado em jun.

2011 de http://video. globo.com/Videos/

Player/Noticias/0, GIM

13737717823BRASIL

$+\mathrm{E}+\mathrm{SEGUNDO}+\mathrm{MAI}$

OR+CONSUMIDOR+

MUNDIAL+DE+RITA

LINA,00.html ou http://

www.youtube.com/wat

$c h ? v=$ MTFOb2bLjLA\&f eature $=$ related

\section{O Brasil é o segundo maior consumidor} mundial de Ritalina, uma droga indicada para crianças diagnosticadas com algum distúrbio no aprendizado escolar. Só no ano passado, foram consumidas quase dois milhões de caixas do medicamento, situação que preocupa os especialistas em educação. É difícil resistir à tentação, principalmente se o remedinho promete resolver o problema das crianças na escola. Depois dos EUA, o Brasil é o país que mais usa Ritalina. Por aquietar crianças diagnosticadas como hiperativas, o medicamento ganhou um apelido: a droga da obediência. Foram 70 mil caixas vendidas em 2000. Nove anos depois, o consumo chega a 1.700 .000 caixas... a prescrição de drogas para crianças com supostos distúrbios de convivência social e de aprendizado subiu $940 \%$ em 4 anos. São médicos que prescrevem esses medicamentos. O que está acontecendo?' 
2 Drª Maria Aparecida Moysés, professora do Departamento de Pediatria da UNICAMP, em entrevista no momento da referida matéria jornalística, afirma que tal medicamento teria o mesmo mecanismo de ação das anfetaminas e da cocaína, com reações adversas em todos os sistemas do organismo e alta toxidade.

3 “Para Rabinow (1999), devemos entender por tecnologia um conjunto de operações e procedimentos que marcam as junções e relações entre o saber e o poder, e é nesse prisma que tanto a disciplina quanto a biopolítica são enfocadas por Foucault"

(Caliman, 2001, p.19).

4 O termo é de Ivan Illich, que, no seu livro Medical Nemesis: a Expropriação da Saúde, de 1975, descreve uma invasão, pela Medicina, de esferas cada vez mais diversas da vida (Boarini \& Yamamoto, 2004).
Com o tema A droga da obediência, a discussão gerada por matéria divulgada na mídia televisiva e na rede virtual trata do crescimento alarmante de diagnósticos de distúrbios neurológicos de aprendizagem e da prescrição de medicamentos para tais, como a Ritalina ${ }^{2}$, um medicamento cujo princípio ativo é o cloridrato de metilfenidato, um estimulante. No presente artigo, interessanos colocar em análise que modos de funcionamento e lógicas se encontram em jogo. Ao tomarmos tal matéria como analisador, objetivamos problematizar a montagem do regime disciplinar com suas instituições formais e a ampliação de seu alcance para, a partir daí, propor novas possibilidades no que tange a maneiras de colocar-se em análise a questão da não aprendizagem. E, ainda, de possibilitar a emergência de outros modos de intervenção e de invenção de si e do mundo, como é o caso de uma clínica-política, a partir de uma desnaturalização do indivíduo infantil apartado de um plano coletivo de forças, em outros termos, de certo modo de subjetivação implicado com uma política de individualização, de assujeitamento (Coimbra \& Monteiro de Abreu, 2005). Partindo do pressuposto de que a droga é prescrita para comportamentos desviantes e que milhares de crianças são medicadas, uma outra lógica se afirma cada vez mais: a da normatização. Institui-se, dessa forma, o que é ser uma criança normal, saudável e com o máximo de aproveitamento de suas capacidades cognitivas. Assim, o discurso da medicalização se capilariza para outras esferas do existir, medicalização como uma estratégia que transcende o ato de prescrever remédio.

Este artigo visa a problematizar que - mesmo diante da denominada crise das instituições formais - o poder regulador se insere no indivíduo, entendido como a mais ínfima partícula da sociedade moderna, na qual a medicalização constitui não apenas uma norma (índice de normalidade) de adequação ao regime mas também de produção de vida, de modos de existência. Poder-se-ia pensar em quaisquer dos milhares de medicamentos à disposição no mercado: dos antipsicóticos mais potentes e repletos de reações adversas aos afrodisíacos naturais, que servem de apoio à dietética sexual em voga. Foucault (1979) coloca em discussão um outro modo de operar o poder, de gerir a vida e os modos de existência: o biopoder, no presente contexto, seria um poder que estabelece uma política da atenção, da aprendizagem, do comportamento ideal. Tal intento ocorre sutilmente e prescreve também uma regulação dos corpos, um acompanhamento tanto da eficiência quanto do bem-estar, do viver bem, do prazer em brincar, em aproveitar uma leitura ou filme, em suma, do existir em toda a sua extensão. Isso se daria com o apoio, em última instância, das instituições visíveis, como a escola e a clínica médica. Nesse cenário, parecemos ver encarnadas, em uma medicação, o que Foucault (2005) chamou de tecnologias ${ }^{3}$ do biopoder, não mais instituições totais, mas medicações totais. O que se vê é a medicalização ${ }^{4}$ da vida.

\section{O biopoder}

Foucault, ao tratar o biopoder em sua obra, o caracterizará como uma nova tomada da vida pelo poder, que não é mais o do soberano de "fazer morrer e deixar viver", mas o de um poder sobre a vida. O biopoder distingue-se da soberania na relação que cada um tem com a vida e a morte: enquanto o soberano faz morrer e deixa viver, o biopoder faz viver e deixa morrer. “(...) É o fato de o poder encarregar-se da vida, mais do que a ameaça de morte, que lhe dá acesso ao corpo" (Foucault, 1999, p.134). A lógica do poder do soberano era negativa: tratava-se de subtrair a vida, em um sentido amplo, os bens, o trabalho, a riqueza, de apropriar-se das coisas, do tempo, de corpos, de vida, sendo um poder limitativo, restritivo, mecânico, 
Foucault (1979) insere a vida na história.

É quando o biológico incide sobre o político, o poder incide sobre seres vivos, de cuja vida ele deve encarregarse; a vida e seus mecanismos entram nos cálculos do poder e do saber, enquanto estes se tornam agentes de transformação da vida. expropriador. No período clássico, o poder passa a funcionar na base da incitação, do reforço, do controle, da vigilância, em suma, da otimização das forças que ele submete. Nesse novo regime, o poder produz forças e as faz crescer, ordenando-as. Ele se ocupa de gerir a vida mais do que exigir a morte. Se antes se tratava de defender a soberania de um Estado (lógica da soberania), trata-se agora de garantir a sobrevivência de uma população (lógica biológica). Mesmo quando a ordem é matar, é a vida de uma população que está em jogo; matar para poder viver, sobreviver.

Há duas formas que configuram esse fazer viver, ou seja, o biopoder: a disciplina e a biopolítica. A primeira caracteriza as instituições como escolas, hospitais, fábricas e efetua-se na docilização e na disciplinarização do corpo, otimizando-o em sua anátomo-política. A segunda forma não incide diretamente sobre o corpo do indivíduo, mas no corpo-espécie, sobre a população como espécie humana, suporte de processos biológicos, na proliferação, nos nascimentos e na mortalidade, mas também no nível de saúde (Pelbart, 2003).

Anátomo-política e biopolítica são formas que se atravessam. A disciplina tenta reger a multiplicidade dos homens como indivíduos sujeitos à vigilância, ao treino e eventualmente à punição; a biopolítica se dirige à multiplicidade dos homens como massa global, afetada por processos próprios à vida, como a morte e a produção de doenças. Ao descrever a gênese da biopolítica, Foucault (1979) insere a vida na história. É quando o biológico incide sobre o político, o poder incide sobre seres vivos, de cuja vida ele deve encarregar-se; a vida e seus mecanismos entram nos cálculos do poder e do saber, enquanto estes se tornam agentes de transformação da vida. Fica fácil deduzir o crescente protagonismo que a Medicina passa a exercer em um cenário em que outrora a figura do soberano, absoluto, solar, permanecia intocável.

Com o surgimento do Estado moderno, em especial, na Alemanha, a população torna-se protagonista de alguns direitos e passa a ser entendida como parte da nação; a Medicina social se articula à força estatal. Deve-se destacar que, nessa Medicina social que protagoniza um papel no regime disciplinar, como chama a atenção Foucault em sua conferência sobre o nascimento da Medicina social, o Estado prussiano precisava mostrar a sua força, através dos corpos de seus funcionários, de seus exércitos e, muito antes da higienização francesa e da produtividade do proletário inglês, incluiu a saúde como um problema de Estado, e a Medicina se transformou, exercendo um controle maior de vigilância sobre a população e sobre a própria atividade dos médicos.

Da vigilância total sobre os corpos das populações, ação da polícia médica alemã, passando pelo sanitarismo francês e pela medicina dos pobres inglesa, o poder disciplinar da tecnologia médica foi avançando aos dias atuais, tomando diferentes formas, usando diferentes estratégias - suas biopolíticas -, mas segue com o mesmo status naquilo que Deleuze (1992) chamou de sociedade de controle. Inclusive, pode-se dizer que é a biopolítica um dos mecanismos que opera a transição da sociedade disciplinar para a sociedade de controle. Somente esse tipo de sociedade pode adotar o contexto biopolítico como terreno de referência, já que a sociedade disciplinar não conseguia penetrar inteiramente nas consciências e nos corpos dos indivíduos a ponto de organizá-los na totalidade de suas atividades.

Na sociedade de controle, o conjunto da vida social é abraçado pelo poder e desenvolvido na sua virtualidade, subsumida na sua integralidade e não apenas na materialidade, que, aliás, apresenta outro 
O corpo é uma realidade biopolítica. A Medicina, uma estratégia biopolítica" (1979, p.80). tratamento em relação ao trabalho. Através deste, de forma imaterial, produzem-se não só aparelhos domésticos e alimentos mas também informação, conhecimento e imagens, transbordando o tempo de trabalho para coincidir com o tempo de vida, confundindo tempo de produção e de reprodução. Esse trabalho depende da criatividade coletiva, tende a funcionar em rede, deriva da cooperação intelectual, instaura espaços comuns de produção e nem por isso deixa de ser explorado pelo capital à medida que é investido, estimulado. $\mathrm{O}$ capital encontra aí, nessa força-invenção do potencial cognitivo, disseminada por toda parte, uma reserva inesgotável.

\section{A medicalização da vida como estratégia biopolítica}

É em O Nascimento da Medicina Social que Michel Foucault emprega pela primeira vez o termo biopolítica. O autor alia o capitalismo à socialização do corpo, à lógica biopolítica, e cita, nessa mesma obra: "Foi no biológico, no somático, no corporal, que, antes de tudo, investiu a sociedade capitalista. O corpo é uma realidade biopolítica. A Medicina, uma estratégia biopolítica" (1979, p.80).

O hospital passa a ser regido disciplinarmente no século XVIII, acarretando mudanças drásticas que resultam no modelo hospitalar encontrado nos dias atuais. Essas mudanças objetivavam fazer o hospital deixar de ser um lugar somente de assistência e passar a ser um local também de exclusão de pobres doentes, de moribundos, visto como lugar não só de proliferação de doenças no seu interior mas, sobretudo, de contágio com o exterior, ou seja, com o meio urbano que se avolumava em seu entorno. A utilidade do hospital se assentaria na cura das doenças, teria uma função terapêutica que, para tanto, se disciplinaria organizando-se tanto seu espaço externo - sua localização na cidade - quanto interno - na classificação dos doentes, na organização das equipes, no controle dos fluxos de ar, água e pessoal -, já que a cura das doenças se daria na gestão da ação do meio sobre os indivíduos, como a Medicina da época propunha. A disciplina introduz o saber médico no hospital, que passa a disciplinar-se também quanto à constituição de seu saber, deixando de ser as experiências individuais, com o sucesso de determinadas terapêuticas, processos de cura miraculosos e casos espetaculares para ser mais as observações diárias dos pacientes nos leitos, o acompanhamento dos doentes em uma rotina hospitalar registrada exaustivamente, a troca de experiências com outros médicos, a acumulação e a formação do saber. Para obter esse controle populacional, tornou-se necessário isolar os doentes individualmente, saber da evolução de cada um em seu leito: “(...) o indivíduo e a população são dados simultaneamente como objetos de saber e alvos de intervenção da Medicina, graças à tecnologia hospitalar" (Foucault, 1979, p. 111).

Portanto, não se tratava mais de excluir a pobreza, mas de inseri-la na cidade, pois era importante economicamente que ela se mantivesse, mas como um índice, limpo, higienizado. Nesse sentido, os hospitais, que antes serviam de depositários asilares de pobres de onde se esperava a morte e a redenção da alma, aliaram-se a uma medicina evidentemente social, pública, que poderia, então, promover a redenção dos corpos. O hospital passa a ter uma finalidade terapêutica, território de pleno exercício do biopoder.

A Medicina torna-se - nas tramas do biopoder - estratégia de disciplina e de regulamentação das populações. Ela ainda normatiza, disciplina o corpo adoecido, mas também prescreve as condições ideais para o bem viver coletivo. "Nesse sentido, a Medicina é um saber que incide ao mesmo tempo sobre o corpo e sobre 
5 Foucault descreve esses insucessos através das experiências em substituir o hospital por outras práticas médicas em seu texto

O Nascimento do Hospital (cf. Microfísica do Poder, pp. 99-111).

6 Sobre o virtual nos processos cognitivos: Kastrup, V. (2007). A invenção de si e do mundo. Uma introdução do tempo e do coletivo no estudo da cognição. Belo Horizonte: Autêntica. a população, sobre o organismo e sobre os processos biológicos, tendo, portanto, efeitos disciplinares e efeitos regulamentadores" (Foucault, 2005, p. 302). O hospital, apesar das várias tentativas de subtração ${ }^{5}$, resiste; parece haver uma certa necessidade da corporificação desse modelo disciplinar, um lugar de excelência para a prática médica, haja vista a solicitação sempre constante da população por mais saúde coincidir com a de construção de mais hospitais.

No Brasil, o modelo do Programa Saúde da Família vem suprir as limitações físicas e operacionais do hospital, de ampliar geograficamente o alcance do saber médico, sobretudo nas cidades do interior, onde a zona rural ocupa grande importância. Entretanto, nada consegue propagar de forma tão imperiosa o saber médico quanto a medicalização, exatamente por sua sutileza e potencialidade na diluição das figuras do médico e do hospital, do saber e do cuidado ao alcance de todos, uma forma capilar do hospital que investe sobre o corpo social e o corpo físico, sobre a virtualidade do corpo, sobre o seu potencial cognitivo inscrito na experiência com o tempo ${ }^{6}$.

A medicalização, como apontam Boarini e Yamamoto (2004), foi um conceito cunhado pelo filósofo, historiador e crítico social Ivan Illich, em 1975. No entanto, há que se considerá-lo um processo histórico, amplamente abordado em diversos campos e tradições de pensamento. Definimos aqui medicalização da vida como um processo bastante imbricado com a sociedade de nosso tempo, na qual o saber médico se estende às mais diversas áreas implicadas com o bem-estar humano. Problemas cotidianos do existir, como sexualidade, infelicidade, degradação biológica, envelhecimento, solidão e morte, passando pelas várias etapas da vida, desde os recém-nascidos, às crianças e mulheres grávidas até as que estão no climatério e os que chegaram à velhice, são tratados sob a égide da Medicina e de seus cuidados em termos de problemas médicos, ou seja, de doenças, síndromes ou condições (Abreu, 2006; Caliman, 2001; Boarini \& Yamamoto, 2004; Moysés, 2001, Moysés \& Colares, 2007).

Para que a medicalização e a intervenção especialista se justifiquem, faz-se necessária a criação de patologias que deem nome aos desvios, à diferença, à desobediência das normas, afirmando-se o que é ser normal. Dessa forma, é possível a captura do viver pelo discurso biomédico. As patologias são tornadas visíveis para que se invisibilizem as formas consideradas desviantes de vida no existir atual. Moysés e Colares apontam a naturalização, a partir de um discurso médico, de comportamentos transformados em anormalidades:

Nessa década, 'comprovou-se' que a agressividade era biologicamente determinada por cérebros disfuncionais, e a solução proposta e implantada para a violência nos guetos foi a psicocirurgia, eufemismo para a lobotomia; também foi 'provado' que a inteligência é geneticamente determinada, e que os negros são, naturalmente, inferiores aos brancos; 'provou-se' ainda que, geneticamente, as mulheres desenvolvem menos os raciocínios matemático e abstrato, o que explicaria sua maior dificuldade de inserção no mercado de trabalho e a ocupação em cargos de chefia. Isso sem falarmos das teorias de Lombroso e, em especial, de suas releituras recentes (2007, p. 165)

O conceito de medicalização pode ser entendido como um processo que produz realidade e conforma modos de existir. É um processo que fabrica subjetividades medicalizadas, produz modos de existência e gerência de vida, de saúde. Interessa-nos, neste momento, pensar sobre uma etapa da vida sobre a qual a medicalização incide, ao mesmo tempo em que a produz: a infância. Partimos do pressuposto de que é desde o princípio que se medicaliza, na concepção 
7 Pertencentes ao movimento médico-higienista, tais profissionais se valem de uma lógica de controle do corpo individual, o corpo físico, mas, principalmente, têm como maior objetivo o controle do corpo social. Esse movimento visava a enquadrar os sujeitos em normas ditas adequadas de higiene física, bem como em normas morais. $\mathrm{O}$ movimento chega ao Brasil no final do século XIX procurando melhorar as condições do meio $\mathrm{e}$ as individuais em nome de uma melhoria do estado físico do homem (Boarini \& Yamamoto, 2004). Sobre a gênese desse poder no Brasil colonial, ver Costa, Jurandir Freire, Ordem Médica e Norma Familiar. Rio de Janeiro: Edições Graal, 1999. da vida, quando esta é forjada. De que modo o saber médico se apropria da infância ao mesmo tempo em que produz um saber sobre ela?

\section{A apropriação da infância pelo saber médico}

As relações de saber-poder que incidem sobre a infância e o que entendemos a respeito do ser-criança no contemporâneo são efeitos emergentes de uma luta de forças múltiplas, que se atualizam em formas visíveis e dizíveis de um modo de subjetivação dominante, forças que forjam uma relação entre saúde e infância, fazendo entrar em cena o tema da medicalização como tecnologia de assujeitamento e de controle de riscos. Na experiência brasileira, a medicalização da infância evidenciou-se no âmbito educacional, quando, no advento da República, buscava-se a constituição da imagem do cidadão brasileiro. Para tanto, a família, e, em especial, a criança (futuro cidadão, futura mão de obra, futuro consumidor), tornam-se foco de intervenção médica. A medicalização, como estratégia biopolítica, serviu à constituição da nação e à afirmação da classe dominante burguesa, que oferece os moldes de vida da família brasileira. Nesse contexto, a escola é o lugar, por excelência, de constituição dos corpos saudáveis e educáveis. Abreu pontua:

O tema da infância e adolescência marcou presença no período republicano. Os princípios da Escola Nova, ou seja 'a corrente que trata de mudar o rumo da educação tradicional, intelectualista e livresca, dando-lhe sentido vivo e ativo', determinaram importância privilegiada para o estudo da criança, colocando-a no centro do processo educacional. O homem moderno, esse novo homem, exigido pela nova ordem urbano-industrial, deveria ser disciplinado, hígido, saudável, ativo e amante da pátria (Abreu, 2006, p. 29)
A valorização do corpo e da vida da criança na modernidade - operadas pela racionalidade e pelo controle médico - é fator de fundamental importância para as tecnologias de biopoder, tecnologias focalizadas no interior da família nuclear.

Modelos ideais de vida burguesa são produzidos, nos quais a criança se torna um importante foco de cuidados. A família é a responsável por proporcionar à criança - futuro trabalhador - bem-estar e oportunidades educacionais que lhe garantam crescimento pessoal.

\begin{abstract}
A família torna-se um campo fértil para as políticas estatais, que passam a gerir a população com o discurso do bem-estar e da proteção das crianças - futuro da sociedade. Aos pais, caberia zelar pelos seus filhos, evitando a intervenção do Estado (Cunha, 2008, p. 28)
\end{abstract}

Educar as famílias traria como consequência a higiene e o maior controle dos espaços públicos. Para esse desafio, são convidados os especialistas da época: os higienistas ${ }^{7}$. Esses profissionais médicos contribuem para a formação da nova família brasileira e para uma mudança na concepção da infância.

De acordo com Abreu (2006), é a partir da biologia, como ciência encarregada de explicar comportamentos, que o corpo da criança passa a ser visto como um corpo biológico. Assim, aquela que se desviava do comportamento instituído como padrão era transformada em doente.

O saber médico adentra o espaço escolar no final do século XVIII, com a missão de identificar os ditos anormais, na medida em que a questão dos problemas de aprendizagem começa a tomar corpo. A causa da não aprendizagem é associada, desse modo, a fatores orgânicos. 
8 O primeiro é o

Decreto $n^{\circ} 17.943$, que criava o Código de Menores do Brasil, também chamado de Código Mello Mattos, e buscará disciplinar os procedimentos para a atenção aos menores de 18 anos, categorizados como: menores abandonados, delinquentes, órfãos e operários; o segundo é aprovado em 1979, pela Lei $n^{\circ}$ 6.697/79, e será o Novo Código de Menores, que irá definir como objeto de sanção e de vigilância os menores em situação irregular, principalmente os ditos menores infratores.

9 Lei Federal $n^{\circ}$ 8.069/90, que regulamentou o Artigo 227 da Constituição Federal de 1988.
A puericultura é um grande exemplo da apropriação do desenvolvimento infantil por parte da Medicina (Moysés, 2001). Trata-se de um campo do saber que se ocupa da concepção, do nascimento e do desenvolvimento da criança, através de um conjunto de instrumentos médicosociais. Temos, assim, um modo de intervir cientificamente na higiene física e social da infância, de modo que as famílias e as escolas eram o principal foco da Medicina, que parte do pressuposto de ignorância da família com relação aos cuidados que a infância exige. As famílias, dessa forma, precisam aprender a cuidar e a educar suas crianças. Costa discorre acerca de uma ordem médica que, já no século XIX, submete a família moderna à tutela dos especialistas capazes de retomar seu equilíbrio e civilidade outrora perdidos. Uma nova organização do espaço doméstico (nefasto à saúde dos filhos) daria conta de um ideal de família no qual a infância poderia ser protegida a partir de sua apropriação médica. Esta se fez "(...) à revelia dos pais. Toda uma série de manobras teóricas mostrava-os como obstáculos à saúde, quando não à própria vida dos filhos, para, em seguida, ensinarIhes a maneira adequada de proteger suas crianças" (Costa, 1989, p. 171). Passou-se a buscar uma educação para a criança com o fim de criar o adulto adequado à ordem médica.

Uma rede de vigilância, marcada pelo olhar médico, forma-se na medida em que a Medicina ocupa todo o espaço social, com a finalidade de proteger a saúde e de identificar e eliminar as patologias; define-se o homem modelo; privilegia-se a normalidade. Temos, assim, um campo especulativo, do qual o senso comum se apropria e que Moysés nos apresenta, em que, "para ter saúde, é preciso ter conhecimentos, e, para aprender, é preciso ser sadio e seu reverso", e, ainda, "a causa da doença é a ignorância, e a causa do não aprender é a doença" (2001, p.175).

\section{A lógica da proteção}

O discurso protetivo tornou-se justificativa para a intervenção médica no interior das famílias desqualificadas por saberes especialistas no que tange à educação de suas crianças, seres que, no último século, passaram a ocupar a cena como sujeitos de direitos. Nesse momento, tratar da infância em termos de políticas públicas passou a significar dar conta de direitos específicos. É no século XX que vemos surgir a Carta de Genebra de 1923, base da primeira Declaração dos Direitos da Criança, em 1924, que, de forma normativa, promove a criação, a valorização, a defesa e a proteção da infância como direitos universais da criança (Ferreri, 2007). No Brasil, os códigos menoristas (de 1927 e 1979) ${ }^{8}$ começam a legalizar concepções de proteção sobre a infância. No entanto, é principalmente na figura do Estatuto da Criança e do Adolescente ${ }^{9}$ (1990) que vemos uma política que entenderá a criança de forma totalizante. Até então, o objeto da proteção era a criança que estava sob risco de marginalidade, o menor carente, em situação irregular. Com o ECA, o paradigma passa a ser o da proteção integral, estabelecendo os direitos fundamentais da infância: à vida, à saúde, à alimentação, à educação, ao esporte, ao lazer, à profissionalização, à cultura, à dignidade, ao respeito, à liberdade e à convivência familiar e comunitária. Tomamos então o acontecimento ECA como dispositivo que faz ver e falar um modo de funcionamento da biopolítica. Ele é um fenômeno que atualiza a lógica da proteção ao seguir uma direção político-pedagógica, em vez de correcional (como nos códigos menoristas). Para Santos e Chaves, o Estatuto "representa o corolário atual de um longo processo histórico de transformação do próprio conceito de infância. Funciona como uma expressão legal e legalizante dessa concepção (...), um marco histórico, no caso brasileiro, em termos de abordagem legal da infância" (2006, p.87). À criança protegida e garantida, é atribuída uma condição natural/ 
normal de desenvolvimento, saúde, enfim, de um modo de vida.

Tal acontecimento pode ser aqui considerado condição de possibilidade para gerência da constituída população infantil. Quando a criança, além de ter um corpo valorizado, passa a constituir uma população com direitos e necessidades específicas, está posto o fundamento para o fortalecimento do exercício do biopoder, que, por conseguinte, serviu de justificativa para a proliferação de instituições de policiamento das famílias. Estas receberam a função de proteger a infância ainda tutelada, pois desprovida legalmente de autonomia. A menoridade seria condição problemática à autonomia e, portanto, à liberdade do sujeito de direitos em geral. A criança foi, portanto, alçada ao âmbito dos direitos humanos sem a condição autônoma e livre do estatuto de sujeito de direitos, porque seria temporariamente incapaz de arcar juridicamente com ela (Ferreri, 2007, p. 68).

A família e o Estado são os responsáveis por zelar pelo cumprimento dos direitos da criança. Há que se manter, então, constante monitoramento de tal responsabilidade. Donzelot associa a constituição de uma polícia das famílias como efeito-instrumento do biopoder.

A polícia tem como objetivo assegurar a felicidade do Estado, através da sabedoria de seus regulamentos, e aumentar suas forças e suas potências tanto quanto ela for capaz. A ciência da polícia consiste, portanto, em regular todas as coisas relativas ao estado presente da sociedade, em consolidá-la, melhorá-la e em agir de forma que tudo concorra para a felicidade dos membros que a constituem. Ela visa fazer com que tudo o que compõe o Estado sirva à consolidação e ao aumento de seu poder, como também à felicidade pública (Von Just, 1768 como citado em Donzelot, 1986, p.12)
Assim, o saber médico vai adentrando outros espaços de gestão, aumentando seu poder de jurisdição. Ele passa a ser produzido dentro de um número cada vez maior de encontros com outras instâncias de controle social, destacando-se dentre elas o sistema legal, o aparato jurídico e o espaço doméstico. Ele vai exercendo poder sobre a vida, ao passo que prescreve para a população normas de higiene e de controle social através da imposição de normas familiares burguesas e da apropriação da infância. Os corpos dos alunos/crianças continuam sendo disciplinados, mas a vida da população também é regulamentada. É a vez da regulação do corpo-espécie. Aí, instituições como família e infância tornam-se alvo de incidência de poder, em uma lógica de proteção e de diminuição de riscos. Como aponta Abreu, as estratégias de biopoder que buscam prevenir riscos vão desenvolvendose e penetrando nas mais diferentes esferas, buscando sempre garantir saúde e vida. Elas "envolvem todos os sujeitos ao longo de toda a vida, com seu imperativo da saúde e seu amplo menu de medidas preventivas: alimentação, esportes, psicofármacos, vitaminas, terapias, etc" (2006, p.66).

\section{A criança como ser consumidor}

A criança, como sujeito de direitos e de necessidades específicas, emergirá nesse contexto, então como mais um ser consumidor de um vasto menu no mercado da saúde. Existe um modo de vida a ser comercializado que envolve tudo aquilo que ela precisa para, como lhe é de direito, crescer sob um modelo de desenvolvimento ideal.

Abreu destaca o período pós-industrialismo, no qual a preocupação não é mais com o homem-máquina, que deve ser docilizado para operar como mão de obra a favor do capital industrial, mas com o homem consumidor de seus produtos, de modos de existência, de necessidades hegemonicamente instituídas e socialmente compartilhadas. É o 
capitalismo comercial. Nesse novo modelo, torna-se possível a substituição da fábrica pela empresa (Deleuze, 1992).

Podemos acrescentar que, com a naturalização de patologias historicamente criadas e de comportamentos tornados periculosos, a lógica da prevenção do risco passa a ser instituída e move a medicalização. Tendência e propensão tornam-se palavras de ordem. Pais, mestres, Estado precisam estar cada vez mais atentos, em nome do bem-estar geral, a qualquer sinal de que a doença bate à porta. Mais do que isso, há que se prevenir tal visita. Para tanto, existe uma escolha: a escolha da vida saudável, dos hábitos saudáveis, das medidas preventivas, do conhecimento/ reconhecimento de condutas inadequadas.

No entanto, no mundo medicalizado e gerido pelo biopoder, escolher implica decidir entre alternativas decidíveis. A escolha já está prescrita em alguma lista socialmente aceita e compartilhada. Ser um aluno agitado, em uma sala onde todos devem comportar-se de maneira oposta, não cabe. O regime atencional ideal precisa obedecer a certos padrões de funcionamento. As reações não podem escapar ao previsto. As necessidades de cada criança já foram anunciadas por um outro alguém - adulto, especialista... O que se faz é, cada vez mais, afirmar uma noção de mundo onde outros mundos não caibam, onde a diferença não cabe e onde a diversidade é medicalizada.

Aproximamos essa realidade de consumo daquilo que Guattari, ao lado de Rolnik (2005), chamou de uma produção de subjetividade capitalística, na qual

(...) o que há é simplesmente uma produção de subjetividade, não somente uma produção de subjetividade individuada subjetividade dos indivíduos - mas uma produção de subjetividade social que se pode encontrar em todos os níveis da produção e do consumo. E mais ainda: uma produção da subjetividade inconsciente. A meu ver, essa grande fábrica, essa poderosa máquina capitalística produz, inclusive, aquilo que acontece conosco quando sonhamos, quando nos apaixonamos, e assim por diante. Em todo caso, ela pretende garantir uma função hegemônica em todos esses campos (...) de natureza industrial, maquínica, ou seja, essencialmente fabricada, modelada, recebida, consumida (2005, pp. 22-23)

A partir de tal apontamento, compreendemos o manejo da subjetividade social, que leva todos a buscarem um modo de vida semelhante, em um sistema de equivalência. Serializados e automatizados, os sujeitos têm seu potencial criativo modulado e dessensibilizado em sua singularidade. As pessoas sentem, pensam, consomem, são avaliadas segundo padrões sociais hegemônicos, padrões esses produzidos em larga escala que legitimam modelos de vida em detrimento de outros.

Para aqueles que ousam levantar a voz e trilhar caminhos singulares, é preciso fazêlo com o máximo de consistência, pois, ao opor-se ao hegemônico, esbarra-se na exigência da subjetividade capitalística de uma imagem de referência, que traz impedimentos quanto ao questionamento a papéis pré-definidos, o que dificilmente é sustentado sem o apoio de um coletivo. Frente a essa realidade, a subjetividade capitalística atua como culpabilização, fazendo com que, por fim, a internalização daqueles papéis seja o fruto do silenciar de um potencial criativo. É a partir da infância, segundo Guattari e Rolnik (2005), que as máquinas de produção da subjetividade capitalística começam a trabalhar, quando essa criança precisa inserir-se no mundo das línguas dominantes.

Assim, um grande mercado se forma, vendendo não apenas produtos mas também discursos que regulamentam a vida, tudo em nome da boa saúde. No exercício 
do biopoder, o principal produto a ser consumido é a saúde. Tal prerrogativa produz a necessidade de cuidados com o corpo, na tentativa de evitar o risco da doença, bem como de detectar possíveis anormalidades. Para tanto, faz-se necessária uma certa vinculação de informações.

O discurso da saúde fortemente veiculado na mídia cria um sistema de alerta para todos. Todo mundo se preocupa em aprender a reconhecer os sinais das doenças para manter uma vida saudável. Abreu afirma:

\begin{abstract}
Trata-se da veiculação, em espaços midiáticos, da idéia de que os processos subjetivos da existência constituem-se como doenças. Dessa forma, um sentimento de tristeza passa a ser imediatamente classificado como depressão, estados de contemplação e devaneio passam a ser rotulados como déficit de atenção, a agitação transforma-se em hiperatividade, e até mesmo uma pirraça infantil passa a ser identificada como TDO - transtorno desafiador opositivo (2006, p.65)
\end{abstract}

No contemporâneo, o biopoder conta com o avanço das tecnologias de comunicação e das biotecnologias. Com a globalização, o que se vê é a hegemonia mundial de um discurso medicalizante, que universaliza patologias, produtos, diagnósticos, saberes... A figura do médico se virtualiza. O paciente cada vez mais adentra os consultórios propondo uma medicação para o diagnóstico que ele mesmo fez. É a saúde como um objeto de consumo, cada vez mais acessível a toda a população. Os acontecimentos que marcam a Medicina e a saúde da segunda metade do século XX possibilitam a constituição de um novo direito, de uma nova moral, de uma nova economia e de uma nova política do corpo (Foucault como citado em Caliman, 2001, p. 47). déficit de atenção/ hiperatividade (TDAH). Para aprofundamento do tema, cf. Calliman, 2009, disponível em: http://www. scielo.br/pdf/psoc/ v21n1/16.pdf
Ali onde a disciplina parece falhar, diante das quais as resistências insurgem, a biopolítica se estabelece insidiosamente limpa e desejada: o educador comparece em forma de comprimidos, sem punições, sem traumas. As disciplinas, que se fariam em oposição às forças da vida, passam a constituir-se com elas na promessa de liberdade, de um viver plenamente através da ativação, do bom funcionamento do sistema cognitivo, que atua na virtualidade, no modo de perceber da criança medicada. Uma medicação que deveria ser exceção, segundo denuncia Moysés (2001), talvez digna de ser prescrita por uma junta multidisciplinar de profissionais, acaba sendo prescrita à revelia, quase como uma vitamina, incrementando os índices epidêmicos do TDAH ${ }^{10}$, sob os indícios perscrutados pelo professor e para alívio dos pais, pois, afinal de contas, o filho não é mal-educado, ele é doente. Desse modo, o "problema é médico, é de remédio".

Entretanto, na sociedade de controle, o biopoder - mesmo disciplinarmente -, não penitencia esse corpo, não o consome, não almeja diminuir dele sua vitalidade; ao contrário. E é exatamente por não mortificar esse corpo, mas por investir, por agitar, que esse corpo pode resistir ao biopoder, criando um território tão insidioso quanto as próprias estratégias biopolíticas da Medicina. Passa pelos pais das crianças, mas também pelos professores, a possibilidade de se reapropriar do capital cognitivo e de lançá-lo nessa rede coletiva evocando enunciados de acolhida de funcionamentos atencionais outros e de revolta à lógica da hiperestimulação, da demanda desenfreada por acúmulo de informação e por resposta automática. Tratase de se reapropriar desse corpo vivo e de inventar sua relação com o tempo, ainda que fora dos eixos, território esse formado pelo que Guattari e Rolnik (2005) chamaram de processos de singularização, ou seja, "tudo que é do domínio da ruptura, da surpresa e da angústia, mas também do desejo, da vontade de amar, de criar" (2005, p.52) e ainda, da "tentativa de produzir modos de subjetivação

\section{Considerações finais}


originais e singulares" (2005, p.54), daquilo que possibilita a criação e a autonomia a partir de uma reapropriação da subjetividade dominante. A singularização é da ordem do desejo, e expressa-se através daquilo que surpreende, que rompe, que angustia. É nesse território, de singularidades, que apostamos como possibilidade de atuação profissional em tempos de operação do biopoder, na forma de uma clínica-política (Passos \& Barros, 2009).

Se falávamos de um poder sobre a vida, também falamos de uma política sobre a vida. A clínica-política surge como uma forma de resistência ao assujeitamento, por meio da liberdade e da criação. É isso que potencializará uma prática no campo da intervenção clínico-política em um mundo dominado por um poder que se apropria da vida. A intercessão da política com a clínica possibilita bifurcações. Estas desestabilizam o natural, o já-dado, clínica que produz subjetividades, que produz outros modos/ territórios de existência e, ainda, clínica como potência de se criar e de se recriar a cada instante. Trata-se de uma clínica que o tempo todo se encontra com os modos de produção, de subjetivação, ou seja, que está em relação com os processos de produção de subjetividade. Compreendê-la dessa forma "implica, necessariamente, que nos arrisquemos numa experiência de crítica/ análise das formas instituídas, o que nos compromete politicamente" (Passos \& Barros, 2009, p.163).

Apoiadas nos estudos de Michael Foucault, as autoras Coimbra e Monteiro de Abreu ajudam-nos na reflexão de uma prática em que a clínica e a política se encontram e não se dissociam. Indentificamo-nos, então, com esse fazer que questiona os modos hegemônicos de subjetivação, com uma clínica que se entende como produto e produção e, ainda, "como atitude de intervenção que produz políticas de subjetivação, seja na perspectiva passiva do assujeitamento aos valores vigentes, seja na perspectiva ativa de produção de outros modos de subjetivação" (Coimbra \& Monteiro de Abreu, 2005, p. 47). Apostamos na segunda perspectiva, ao incluirmos em nosso fazer o plano coletivo de forças que constituem os sujeitos bem como as práticas políticas que definem o modo de viver dos homens, buscando dar sustentação à invenção de outros mundos e a outras formas si, desviantes das normas dadas. Trata-se de uma militância clínicopolítica que empreende lutas e resistências a um certo modo de exercício do poder, individualizante e reducionista, na produção da forma homem.

Passos e Barros (2009) afirmam a dimensão política da clínica. Esta é definida como clinamem, ou seja, que opera desvio, fazendo bifurcar o percurso da vida na criação de novos territórios existenciais. Uma prática que se comprometa com tal operação precisa colocar em questão o próprio especialismo no qual pode estar alocada, especialismo que nos faz debruçar sobre um objeto dado a priori, que limita intervenções e problematizações, bem como nos faz naturalizar e individualizar questões em imagens identitárias.

O que se propõe, a partir de então, é a desnaturalização da norma em prol da busca por caminhos singulares, é atravessar o campo de reflexão do saber médico a respeito da criança por devires, e não como um dado natural, entendendo a escola, a Medicina, a infância e seu desenvolvimento como uma produção histórica e social. Quando falamos em produção, referimonos a processos de invenção de modos de ser, de possibilidades de existência que não param de se recriar. Dessa forma, temos a possibilidade de pensar sobre a criança e sobre sua maneira de aprender, conhecer, ser e estar no mundo a partir de uma perspectiva temporal, coletiva e inventiva. 
À Psicologia, caberia dar voz aos aprendizados que estão fora da escola, que devem igualmente ser trazidos em sua legitimidade: o aprendizado das ruas, das coletividades ditas marginais, das forças da natureza, dos encontros. A invenção da própria infância em seus desvios com relação ao modo adulto faz emergir sua dimensão errática, multifacetada, em devir, ou seja, o que ainda não se tornou um. Com isso, poder-se-ia pensar na revelação de uma outra face da escola: o lugar de encontro, antes de ser o lugar da disciplina por excelência, o lugar de fazer ver o que a criança ensina. 


\section{Kely Magalhães Decotelli}

Doutoranda em Psicologia pela Universidade Federal do Rio de Janeiro, Rio de Janeiro - RJ - Brasil.

E-mail: kelydecotelli@gmail.com

\section{Luiz Carlos Teixeira Bohrer}

Doutorando em Psicologia pela Universidade Federal do Rio de Janeiro, Rio de Janeiro - RJ - Brasil.

E-mail: lucatb@gmail.com

\section{Pedro Paulo Gastalho de Bicalho}

Doutor em Psicologia pela Universidade Federal do Rio de Janeiro e docente do Instituto de Psicologia e do Programa de Pós-Graduação em Psicologia da Universidade Federal do Rio de Janeiro, Rio de Janeiro - RJ - Brasil E-mail: ppbicalho@ufrj.br

Endereço para envio de correspondência:

Avenida Pasteur, 250, Pavilhão Nilton Campos, Campus Praia Vermelha. CEP: 22290-240. Rio de Janeiro, RJ.

Recebido 03/06/2011, 1a Reformulação 07/01/2013, Aprovado 22/01/2013.

Abreu, H. R. M. (2006). A medicalização da vida escolar. Dissertação de mestrado. Escola de Educação, Universidade Federal do Estado do Rio de Janeiro, Rio de Janeiro, RJ.

Boarini, M. L., \& Yamamoto, O. H. (2004). Higienismo e eugenia: discursos que não envelhecem. Psicologia Revista, 13(1), 59-72.

Brasil. República Federativa (1990). Estatuto da criança e do adolescente (Lei №. 8.069, de 13 de julho de 1990). Brasília, DF: Autor.

Caliman, L. V. (2001). Dominando corpos, conduzido ações: genealogias do biopoder em Foucault. Dissertação de mestrado. Instituto de Medicina Social, Universidade do Estado do Rio de Janeiro, Rio de Janeiro, RJ.

Coimbra, C. M. B., \& Monteiro de Abreu, A. M. R. (2005). Quando a clínica se encontra com a política. In S. Tedesco, A. Maciel Junior \& D. Kupermann (Orgs.). Polifonias: clínica, política e criação. Rio de Janeiro: Contra-capa.

Costa, J. F. (1989). Ordem médica e norma familiar (3a ed.) Rio de Janeiro: Graal.

Cunha, F. L. (2008) Destituição do poder familiar no espaço do Conselho Tutelar: abandono, maus-tratos e negligência de quem? Dissertação de mestrado. Departamento de Psicologia, Universidade Federal Fluminense, Niterói, RJ.

Deleuze, G. (1992). Post-scriptum sobre as sociedades de controle. In G. Deleuze. Conversações. (pp. 219-226, P.P. Pelbart, trad.). Rio de Janeiro: Ed. 34.

Donzelot, J. (1986). A polícia das famílias (M. T. C. Albuquerque, trad.). Rio de Janeiro: Graal.

Ferreri, M. A. (2007). Mostruário de discursos profissionais sobre psicologia e direitos da infância. Tese de doutorado. Instituto de Psicologia, Universidade do Estado do Rio de Janeiro, Rio de Janeiro, RJ.

Foucault, M. (1979). O nascimento da medicina social. In M Foucault Microfísica do poder. (R. Ribeiro, trad.). Rio de Janeiro: Edições Graal.

Foucault, M. (1999). História da sexualidade I: a vontade de saber (13a ed.) Rio de Janeiro: Graal.

Foucault, M. (2002). Os anormais. São Paulo: Martins Fontes.

Foucault, M. (2005). Em defesa da sociedade (4a ed., M. A. Galvão, trad.) São Paulo: Martins Fontes.

Guattari, F., \& Rolnik, S. (2005). Micropolítica. Cartografias do desejo (7a ed. rev.). Petrópolis, RJ: Vozes.

Moysés, M. A. A. (2001). A institucionalização invisível: crianças que não aprendem na escola. São Paulo: Mercado das Letras.

Moysés, M. A. A., \& Colares, C. A. L. (2007). Medicalização: elemento de desconstrução dos direitos humanos. In Comissão de Direitos Humanos do CRP-RJ (Org.). Direitos humanos? O que temos a ver com isso? Rio de Janeiro: Conselho Regional de Psicologia.

Passos, E., \& Barros, R. B. (2009). Clínica, política e as modulações do capitalismo. In J. C. Mourão (Org.). Clínica e política 2: subjetividade, direitos humanos e invenção de práticas clínicas. Rio de Janeiro: Abaquar/ Grupo Tortura Nunca Mais.

Pelbart, P. P. (2003). Vida capital: ensaios de biopolítica. São Paulo: lluminuras.

Santos, G. L., \& Chaves, A. M. (2006). Proteção e promoção da infância: tensões entre coletivismo e individualismo no Brasil. Interação em Psicologia, 10(1), 83-90. 